\title{
BREVES APUNTES SOBRE EL SENADO Y LOS ENTES LOCALES
}

\author{
PABLO GARCÍA MEXIA \\ Letrado de las Cortes Generales \\ Profesor Doctor de Derecho Constitucional \\ Universidad Carlos III
}

SUMARIO

I. El Senado está llamado a representar a los territorios.

II. Los territorios españoles no son sólo las comunidades autónomas.

III. El Senado ha venido siendo ineficaz en la labor de representación territorial, muy singularmente respecto de las entidades locales.

IV. Un Senado eficaz en la representación de las entidades locales sería sin embargo defendible desde la política y viable desde la técnica jurídica.

V. Epílogo: La posible reforma constitucional del Senado actualmente en curso hace especialmente oportuno el momento de propugnar un Senado eficaz en la representación de las entidades locales.

\section{EL SENADO ESTÁ LLAMADO A REPRESENTAR}

\section{A LOS TERRITORIOS}

El tenor del artículo 69.1 CE ("El Senado es la Cámara de representación territorial") no deja duda alguna acerca de esta idea, ad nauseam conocida. Este factor de representatividad territorial es por lo demás la principal razón de ser de nuestra Cámara Alta. O cuando menos una de ellas, pues como toda "segunda Cámara", carga con el lastre de no disfrutar de "esencia independiente", sino tan sólo de esencia per relationem, siendo lógicamente esa relación con la 
llamada Cámara Baja (electa por sufragio universal para representar directamente a la soberanía popular).

De ahí la furibunda opinión anti-senatorial de algún clásico (Sieyès), para quien las Cámaras Altas resultaban, "O redundantes, o desagradables": redundantes, cuando sus decisiones se limitan a secundar las de la Cámara Baja; desagradables, cuando una y otra decisión divergen, rivalizando así el Senado con la única Cámara que incuestionablemente representa la "voluntad general".

Desde el mismo siglo XVIII, la configuración a que venimos refiriéndonos ha venido esencialmente siendo doble: la de una Cámara de reflexión o "segunda lectura", y la de, justamente, una Cámara de representación territorial.

\section{LOS TERRITORIOS ESPAÑOLES NO SON SÓLO LAS COMUNIDADES AUTÓNOMAS}

Como es también de sobra conocido, ello se desprende del artículo $137 \mathrm{CE}$, al establecer que "el Estado se organiza territorialmente en municipios, en provincias y en las Comunidades Autónomas que se constituyan. Todas estas entidades gozarán de autonomía para la gestión de sus respectivos intereses". Al fin y al cabo, las entidades locales (EE.LL.) preexistían a la Constitución, y desde luego a las CC.AA. Basta comprobar la frase "...que se constituyan" del propio artículo 137 CE.

Sucede empero además que las EE.LL., y en especial los municipios, constituyen el mejor exponente de libertad y de democracia. Por contraste, así lo demuestra el caso del municipalismo latinoamericano: como revela Brewer Carías (2001), una de las principales debilidades de las democracias en la América hispana radica en el muy escaso número (en comparación con Europa) de sus municipios, lo que hace difícil que la democracia se sienta por los ciudadanos como algo propio y cercano. Por sólo poner un ejemplo: España, con 44 millones de habitantes y poco más de $500.000 \mathrm{~km} 2$, cuenta con más de 8.000 municipios electos y una relación población/municipio de unas 5.500 personas; Venezuela, con unos 25.000.000 de habitantes, sólo dispone de 338 municipios electos, con una ratio población/municipio de unas 72.000 personas.

Es principalmente por ambas razones (singularmente por la segunda), por lo que la Constitución atribuye también a las EE.LL. «autonomía para la gestión de sus respectivos intereses" (art. 137 CE), anticipándose a lo que poco después (en 1985) exigirían la Carta Europea de Autonomía Local (art. 3.1) y la Ley de Bases de Régimen Local (art. 2.1) ${ }^{2}$. En estos mismos términos vino también a

1 Conforme al citado artículo 3.1 de la Carta Europea de la Autonomía Local (CEAL), "por autonomía local se entiende el derecho y la capacidad efectiva de las entidades locales de ordenar y gestionar una parte importante de los asuntos públicos, en el marco de la ley, bajo su propia responsabilidad y en beneficio de sus habitantes."

2 Según el artículo 2.1 de la mencionada Ley $7 / 1985$, de 2 de abril, reguladora de las Bases del Régimen Local (LBRL), «la legislación del Estado y de las Comunidades Autónomas deberá asegurar a municipios, provincias e islas su derecho a intervenir en cuantos asuntos afecten directamente al círculo de sus intereses". 
pronunciarse el Tribunal Constitucional, al proclamar que la autonomía local es "el derecho de la comunidad local a participar, a través de órganos propios, en el gobierno y la administración de cuantos asuntos le atañan" (STC 32/1981, de 28 de julio; de forma muy similar se expresaría el Tribunal en su sentencia de 27 de febrero de 1987). Mientras que en la STC 214/1989, de 21 de diciembre, el Tribunal proclamaba que a las EE.LL. asiste un "derecho a intervenir en cuantos asuntos afecten directamente al círculo de sus intereses".

Una autonomía que no es soberanía. Así lo resaltaba expresamente, en una de sus primeras sentencias, el Tribunal Constitucional, insistiendo en que la noción de autonomía no hace referencia a un poder ilimitado, y en que en ningún caso el principio de autonomía podría oponerse al de unidad (STC 4/1981, de 2 de febrero). En muy semejante línea diría poco después el Alto Tribunal que "Sólo el Estado es titular de la soberanía" (STC 32/1981, ya citada).

Pero una autonomía que, pese a lo inicialmente afirmado por el Tribunal Constitucional y por la primera doctrina post-constitucional, es casi general hoy reconocer presenta la misma naturaleza política (que no meramente administrativa) que la comunitario-autonómica. Así lo asegura Parejo Alfonso (2003, 6566), para quien ambos tipos de autonomía tienen una "sustancia igual", por más que las posibilidades de opción o configuración sean más amplias para las CC.AA., al estar abierto a éstas un cauce en cambio vedado a las EE.LL., la potestad de elaborar leyes formales. En la misma línea se manifiesta sin ambajes Sosa Wagner (2004, 49-60).

Se trata de una autonomía que, de modo bifronte (STC 84/1982, de 23 de diciembre $)^{3}$, protege a las EE.LL., tanto frente a posibles agresiones competenciales del Estado "central", como de las CC.AA., en cuya organización institucional —y pese a la minoritaria opinión de algunos (Font i Llovet 2005) — no pueden considerarse integrables. Por eso afirma con plena razón Parejo Alfonso $(2003,79)$ que no es posible "interiorizar" el poder local en el marco autonómico, pues ello supondría una quiebra del artículo $137 \mathrm{CE}$, que claramente establece tres niveles en la organización territorial del Estado. Y ello por más que, a diferencia de la autonomía propia de las Comunidades, "el contenido funcional de la autonomía local queda permanentemente en la disposición de la ley ordinaria", estando así sujeto a una continua evolución (Parejo Alfonso 2003, 103; y STC 84/1982, citada). Lo cual a su vez explica que el Tribunal Constitucional no tardara en reconocer la necesidad de proteger la "recognoscibilidad" de la autonomía local, apelando a la técnica alemana de la garantía institucional (STC 32/1981, citada; más recientemente, STC de 26 de abril de 1988).

3 Como la referida STC 84/1982 indica, los Entes locales estructuran territorialmente el Estado, al tiempo que se incardinan en el territorio de una Comunidad Autónoma; de acuerdo con ello, el Estado puede reclamar competencias en materia de régimen local al amparo del artículo 149.1.18 $\mathrm{CE}$, en tanto que también pueden hacerlo las CC.AA., a propósito de los Entes locales insertos en su correspondiente territorio, si bien esta vez con respeto a las bases que hubiera podido sentar el Estado, y siempre de conformidad con el bloque de la constitucionalidad en materia de régimen local (esencialmente, el respectivo Estatuto de Autonomía y la LBRL). 
Una autonomía, en suma, que hace de las EE.LL. "Estado", exactamente en la misma medida que su aparato central de poder, o que las Comunidades Autónomas. El llamado Decálogo del Municipalismo del Siglo XXI, incluido en la Carta de Vitoria de 25 de noviembre de 2004, viene acertadamente a reconocerlo, al enunciar en su Punto 10 que "los poderes locales son a la vez órganos de gestión e instituciones públicas"; por ello, son "parte integrante del Estado y conforman uno de los tres niveles de su estructura administrativa, gozando de plena autonomía en las funciones que les son propias y no siendo en ningún caso instituciones de ámbito autonómico".

\section{EL SENADO HA VENIDO SIENDO INEFICAZ EN SU LABOR DE REPRESENTACIÓN TERRITORIAL, MUY SINGULARMENTE RESPECTO DE LAS ENTIDADES LOCALES}

Y ello con independencia de que el Senado haya sido en cambio capaz de sacar adelante sus demás funciones constitucionales (las que a la postre ejerce como una de las dos Cámaras de las Cortes Generales, art. 66.1 CE). De ahí que, de alguna manera, el Senado deba «juzgarse evangélicamente, conforme a la parábola de los talentos", pues es con relativamente pocos "talentos" como a la postre ha venido consiguiendo lo dicho (Laborda Martín 2001).

\section{La inEFicacia del SENAdo EN la REPRESENTACiÓn TERRITORIAL SE HA MANIFESTADO RESPECTO DE LAS CC.AA.}

Como viene siendo general reconocer, así ha venido sucediendo:

A) Primero, en lo que a su composición respecta, pues de entre los 259 senadores, sólo 51 de ellos son designados con arreglo a criterios de representación estrictamente territorial. Se trata, como es sabido, de los denominados senadores designados por las CC.AA., a quienes se refiere el artículo 69.5 CE cuando afirma que las CC.AA. designarán uun senador y otro más por cada millón de habitantes de su respectivo territorio". Y aun respecto de estos "senadores autonómicos", sólo muy relativamente se puede sostener que ejercen una "representación territorial", en la medida en que, exactamente como todos los demás (y del mismo modo que los miembros del Congreso de los Diputados), disfrutan del mandato representativo que sensu contrario consagra el artículo 67.2 CE ( llos miembros de las Cortes Generales no estarán ligados por mandato imperativo"), representando todos y cada uno pues, conforme a la Constitución, a todos y cada uno de los españoles, no solamente a quienes

4 “Las Cortes Generales representan al pueblo español y están formadas por el Congreso de los Diputados y el Senado" (art. 66.1 CE). 
conforman la población de su respectiva Comunidad Autónoma, mucho menos en exclusiva a quienes los designaron, y quedando por tanto completamente inmunes frente a cualquier intento de revocación que los designantes pudieran instar.

B) Segundo, en lo que a su organización concierne, los rasgos representativo-territoriales del Senado esencialmente consisten - junto a algún otro mecanismo como el muy modesto de los llamados grupos territoriales- en la existencia, desde 1994 (merced a una reforma reglamentaria entonces efectuada), de la denominada Comisión General de las CC.AA., a modo de "Senado dentro del Senado". Tras algo más de diez años desde su creación, debe lamentablemente reconocerse que esta Comisión no ha conseguido erigirse ni en el instrumento de integración de las CC.AA. en la adopción de decisiones del Estado, ni en el instrumento de cooperación de las CC.AA. con el Estado y de éstas entre sí, que quizá su propia creación pretendía:

a) En cuanto a lo primero, porque las CC.AA. de mayor peso político, en especial las de gobierno nacionalista, continúan basando su participación en la adopción de decisiones estatales en la negociación bilateral, mientras que las demás lo hacen primordialmente a través de uno de los dos grandes partidos nacionales.

b) En cuanto a lo segundo, porque el grueso de la actividad de la Comisión radica en comparecencias de control a los miembros del Gobierno, en las que los representantes de las CC.AA. que muy desigualmente asisten (la media de asistencia está en unas diez Comunidades por sesión, en tanto que una Comunidad, Euskadi, no asiste nunca a este tipo de sesiones) se limitan a intervenir durante quince o veinte minutos en un debate cerrado, que a lo sumo permite una réplica, y que como mucho permite que unos y otros salgan de él con una idea general de las posiciones de la otra parte, por otro lado conocidas previamente gracias a los foros de cooperación intergubernamental existentes (fundamentalmente, la correspondiente Conferencia Sectorial). A sesiones de otra índole de la Comisión, en particular las legislativas o de dirección política (mediante la aprobación de mociones), los representantes autonómicos, aun pudiendo hacerlo, sencillamente no asisten. Por último, las sesiones de control, únicas a las que como acabamos de ver asisten los representantes de las CC.AA., indudablemente pivotan en torno al miembro del Gobierno compareciente: en una palabra, es casi impensable que este tipo de sesiones puedan tener virtualidad alguna en materia de cooperación horizontal o interautonómica, más allá de los informales contactos —en realidad "de pasillo" — que los representantes de las CC.AA. puedan entre ellos efectuar, y que no serían sino fugaz correlato de los que con habitualidad desarrollan en foros como los citados de cooperación intergubernamental.

En suma, y por todo lo dicho, la Comisión General de las CC.AA. es hoy "una Comisión más del Senado", por más que en sus sesiones puedan intervenir representantes autonómicos, o que su número de miembros duplique al del resto de las Comisiones, e incluso por más que, tras la reforma reglamentaria operada por acuerdo del Pleno de 29 de junio de 2005, cualquiera de las len- 
guas cooficiales en alguna Comunidad Autónoma vaya a poder ser en adelante utilizada en todas sus sesiones.

C) Tercero, en lo que a sus funciones se refiere. No es éste el lugar apropiado para estudiar a fondo la cuestión, de ahí que debamos limitarnos a apuntar las principales ideas, al hilo de las funciones legislativa y de control: en lo que toca a la legislación, y salvo en un caso muy concreto ${ }^{5}$, el Congreso de los Diputados tiene siempre prioridad de tramitación frente al Senado ${ }^{6}$; en tanto que el artículo 90.2 CE constriñe muy severamente la potestad legislativa de la Cámara Alta, fundamentalmente al forzarla a tramitar los textos legislativos procedentes del Gobierno o del Congreso en tan sólo dos meses (cuando no existe limitación temporal global para el propio Congreso de los Diputados) ${ }^{7}$, sin perjuicio de "la potestad de la última palabra" que el mismo artículo 90.2 CE concede en todo caso al Congreso, al permitirle superar por mayoría simple las enmiendas del Senado, o por mayoría absoluta los vetos (que también pueden superarse por mayoría simple trascurridos dos meses desde su interposición). A propósito del juego combinado responsabilidad política-control político, el Senado queda del todo marginado de la exigencia de responsabilidad política al Gobierno (art. $108 \mathrm{CE}$ ), pudiendo en cambio ser disuelto por el Presidente del Gobierno (art. 115) a la par que el Congreso de los Diputados, circunstancia por cierto que, no estando impuesta por el artículo $115 \mathrm{CE}$, ha venido por el contrario siendo — sin excepción alguna — la norma desde el primer Gobierno constitucional; es cierto en cambio que el Senado puede controlar y de hecho controla al Gobierno, si bien, por así decirlo, con un "perfil más bajo" que el Congreso de los Diputados, aunque sólo sea porque casi todas las principales figuras de la mayoría y de la oposición ostentan la condición de diputados, no la de senadores ${ }^{8}$.

D) A modo de síntesis, no está de más recordar la apreciación de la investigadora británica Meg Russell (2000), quien tras analizar las Segundas Cámaras del mundo, y muy especialmente las de siete países occidentales (Canadá, Australia, Irlanda, Alemania, Francia, Italia y España), llegaba a la conclusión de que, junto con el irlandés, el de España es «el Senado más débil del mundo".

5 Se trata de la ley por la que se regula el llamado Fondo de Compensación Interterritorial (art. $158 \mathrm{CE}$ ).

6 Aunque no es estrictamente legislativa, también ha de citarse en este contexto la decisión que adoptan las Cortes Generales a propósito de los denominados acuerdos de colaboración y convenios de cooperación entre las CC.AA., como quiera que constituye el segundo y último ejemplo de tramitación prioritaria del Senado sobre el Congreso (art. 145.2 CE).

Esta prioridad de tramitación del Senado se convierte en exclusividad competencial en el supuesto de la autorización que por mayoría absoluta habría en su caso de conferir el Senado para proceder frente a una Comunidad Autónoma en el excepcional supuesto previsto en el artículo 155 CE, pues en este trámite el Congreso no desempeña papel alguno.

7 Este plazo de dos meses se reduce mucho más aún, hasta los veinte días naturales, respecto de los proyectos declarados urgentes por el Gobierno o por el Congreso de los Diputados (art. 90.3 CE).

8 De hecho, sólo a partir de diciembre de 2004, el Presidente del Gobierno comparece — dos veces al mes- ante el Pleno del Senado, para someterse al question time, que viene en cambio celebrándose de forma tradicional en el Congreso con periodicidad semanal. 
Tal apreciación se revela lógica, sobre todo si la examinamos al socaire de algunas de las mejores aportaciones doctrinales mundiales acerca del bicameralismo. Así Lijphart (1984) clasifica las Segundas Cámaras en función de sus relaciones con las Cámaras Bajas: a) por razón de sus poderes, existirían bicameralismos simétricos, moderadamente asimétricos y extremadamente asimétricos; b) en virtud de su composición, tendríamos bicameralismos congruentes (de similar composición intercameral) e incongruentes. Para Lijphart, el bicameralismo más eficaz combina funciones simétricas o moderadamente asimétricas con composiciones incongruentes, pudiendo considerarse un «bicameralismo fuerte"; sería "débil" el que conjugase sólo una de esas dos características; e "insignificante" el que no contara con ninguna de las dos. Sartori (1997) coincide al aseverar que el bicameralismo más eficaz es el que acumula composición dispar y poderes similares.

Visto lo anteriormente afirmado sobre las funciones del Senado español, cómo dudar de que nuestro bicameralismo resulta "extremadamente asimétrico" en el sentido de Lijphart, pues en casi todos los sentidos es patente su supeditación al Congreso de los Diputados en el ejercicio de sus funciones, estando pues el peso de sus poderes lejos de ser "similar" al de los del Congreso (en el sentido de Sartori). En tanto que si recordamos lo dicho sobre la composición y organización del Senado español, concluiremos con muy semejante facilidad que nuestro bicameralismo es "congruente" en la terminología de Lijphart, pues prácticamente cuatro quintas partes del mismo se eligen por sufragio universal en circunscripciones provinciales (e insulares, además de los casos de Ceuta y Melilla), de forma muy semejante al Congreso (arts. 68.2 CE y 69.2, 69.3 y 69.4 CE), si bien con arreglo a una diferente regla de atribución de escaños ${ }^{9}$, no pudiendo por ende - antes al contrario- sostenerse que su composición sea "dispar" a la del Congreso (en la terminología de Sartori), salvo a propósito de un quinto de sus miembros. La conclusión no puede lamentablemente ser otra que la de considerar, con Lijphart, que el bicameralismo español es "insignificante", al carecer de simetría (o de moderada asimetría) funcional y de incongruencia compositiva; ni siquiera una interpretación generosa del peso de las funciones senatoriales nos llevaría más allá de poderlo considerar "débil", pues el obstáculo de la muy congruente composición es a nuestro juicio insalvable. Si seguimos conceptualmente a Sartori, concluiremos este apartado del mismo modo que lo iniciábamos, proclamando que, cuando menos, el bicameralismo español dista de ser "eficaz". Explicado todo esto, cobra pleno sentido que para García-Escudero Márquez (1998, 209), "cuanto más territorial sea el Senado en su composición, mayor habrá de ser la desigualdad de sus funciones respecto de la Cámara Baja electa por sufragio universal».

9 Regla D'Hondt para el Congreso en lista cerrada y bloqueada, mayoritaria corregida para el Senado (arts. 161 y ss. Ley Orgánica 5/1985, de 19 de junio, del Régimen Electoral General). 


\section{En tanto que la ineficacia del SEnado en la REPRESEntación TERRITORIAL HA PRESENTADO UNA MUY SINGULAR NOTORIEDAD RESPECTO DE LAS EE.LL.}

La necesidad, la conveniencia o ambas, de que el Senado represente también a los EE.LL. ha venido siendo ignorada de modo prácticamente general, tanto por los poderes públicos, como por los sectores académicos, y desde luego por la opinión pública. Baste citar un ejemplo referido al sector académico: no ya ríos, sino "océanos" de tinta son los vertidos a propósito del carácter territorial del Senado; si pudiéramos "explorarlos" todos, comprobaríamos la casi total universalidad de la unilateral interpretación del vocablo "territorial" (art. 69.1 CE) como sinónimo de "comunitario-autonómico". Y si hablamos de "casi total" universalidad, lo hacemos con un doble prurito de modestia y de prudencia, por más que nuestra memoria no alcance a recordar fuente alguna que se aparte de la indicada interpretación.

Y así, la representatividad local del Senado viene a quedar reducida a los siguientes elementos:

A) El carácter indiscutiblemente provincial de 208 de los 259 senadores. Si bien, como indica Ripollés Serrano (1996, 216), "la provincia no es un ente territorial representado en el Senado", como quiera que "los senadores no son elegidos por las provincias, sino en las provincias".

B) Las específicas potestades que la LBRL encomienda al Senado. Entre ellas destaca por su importancia la relativa a la disolución de EE.LL. (art. 61.1 LBRL), en casos de gestión gravemente dañosa para los intereses generales, que suponga incumplimiento de sus obligaciones constitucionales: si bien la disolución obedece finalmente a un acuerdo del Consejo de Ministros, por propia iniciativa de éste o a solicitud del Consejo de Gobierno de la correspondiente Comunidad Autónoma (al que en todo caso debe oírse en el procedimiento), tal acuerdo sólo puede adoptarse una vez se cuente con el parecer favorable del propio Senado.

C) Muy especialmente, la actividad de la Comisión de Entidades Locales de la Cámara ${ }^{10}$, que por cierto a partir de la Legislatura que arrancó en 2004 goza de carácter no ya sólo permanente, sino también legislativo ${ }^{11}$.

10 De la actividad plenaria del Senado en materia de régimen local, durante la Legislatura iniciada en 2004, cabe subrayar: a) dos mociones: en una, que resultó aprobada por unanimidad, se instaba al Gobierno a fijar posición sobre las nuevas fórmulas de financiación local; en una segunda, que fue rechazada, se proponía la constitución de una Ponencia conjunta entre las Comisiones de Administraciones Públicas y Entidades Locales, a fin de redactar una Proposición de ley de bases de régimen local; b) una pregunta, dirigida por el Grupo Popular al Presidente del Gobierno, sobre si en su opinión la reforma de la financiación autonómica debiera o no venir ligada a la mejora de la financiación de las EE.LL.

11 Agradezco muy sinceramente a mi compañero Jorge Villarino Marzo, Letrado de la Comisión de Entidades Locales del Senado, la valiosa información que me ha proporcionado acerca de la realidad cotidiana de esta Comisión, sin la cual muchos de los datos que aquí se vierten habrían quedado por consignar. 
En lo que a su composición respecta, ha de subrayarse la gran abundancia de senadores en mayor o menor medida, en el presente o en el pasado, relacionados con el mundo local (desde antiguos o actuales presidentes de la Federación Española de Municipios y Provincias (FEMP), hasta alcaldes y ex-alcaldes, concejales y ex-concejales, miembros de Diputaciones Provinciales y ex-presidentes de alguna de ellas o de Cabildos Insulares).

En lo que a sus actividades atañe, y dado que no se ha producido en su seno trabajo legislativo alguno desde el inicio de la Legislatura, se centran por una parte en comparecencias de autoridades y expertos (las del Presidente de la Asociación Catalana de Municipios y Comarcas, el Presidente de la Federación de Municipios de Cataluña, el Vicepresidente y Consejero de Presidencia y Relaciones Institucionales de la Diputación General de Aragón, el Presidente de la FEMP (recuérdese, también a su vez senador), o las "ordinarias" de miembros del Gobierno (Vicepresidente 2. ${ }^{\circ}$ y Ministro de Economía y Hacienda; Ministro de Administraciones Públicas) y Secretarios de Estado (Economía, Hacienda y Presupuestos; y Cooperación Territorial). Las actividades se han centrado por otra parte en visitas, destacando - con independencia de las varias relativas al ámbito internacional- la del Ministro de Administraciones Públicas a los miembros de la Mesa y Portavoces de los Grupos en la Comisión, a efectos de informar acerca del Primer Borrador del Libro Blanco para la Reforma del Gobierno Local en España (enero de 2005); y las proyectadas visitas a todas las CC.AA., más Ceuta y Melilla, con objeto de constatar las singularidades del régimen local en todas y cada una de ellas (desde septiembre de 2005).

\section{UN SENADO EFICAZ EN LA REPRESENTACIÓN DE LAS EE.LL. SERÍA SIN EMBARGO DEFENDIBLE DESDE LA POLÍTICA Y VIABLE DESDE LA TÉCNICA JURÍDICA}

En lo que a la defensa política se refiere, así lo ha reclamado la FEMP en el mismo umbral (punto primero) de su Decálogo para el Municipalismo del Siglo XXI. ${ }^{12}$ Esta reivindicación se realiza con expreso apoyo en el método de designación empleado para la designación de la delegación española ante el Comité de las Regiones de la Unión Europea, que como es sabido configura una delegación compuesta de 21 miembros — conforme a las disposiciones comunitarias aplicables-, de entre los cuales 17 son los Pre-

12 Textualmente, se indica en dicho punto: “Garantizar la representación de los poderes locales en el Senado. El artículo 137 de la Constitución organiza territorialmente el Estado en municipios, provincias y Comunidades Autónomas. Para que el Senado pueda desarrollar la identidad de Cámara territorial que le confiere el artículo 69 de la Constitución, su composición debe ser fiel reflejo de esa estructura, integrando tanto la representación de las Comunidades Autónomas, como la de los Gobiernos Locales, tal como se hizo al fijar la representación de la representación del Reino de España en el Comité de las Regiones de la Unión Europea." 
sidentes de las Comunidades Autónomas y cuatro los representantes de las EE.LL. ${ }^{13}$

En lo que a la técnica jurídica atañe, es factible deslindar dos posibles campos de refuerzo de la representatividad del Senado respecto de los EE.LL:

A) Un campo fácilmente edificable (con excepción de lo que más adelante apuntaremos a propósito de una posible iniciativa legislativa de las EE.LL.), la participación de las EE.LL en la elaboración de las leyes. Al fin y al cabo, nos hallamos aquí ante la posible concreción de una exigencia de participación reconocida de modo general en la normativa europea sobre autonomía local ${ }^{14}$, en nuestra propia legislación de régimen local ${ }^{15}$, en muy relevantes ordenamientos comparados $^{16}$, e incluso en el ordenamiento jurídico de algunas de nuestras CC.AA. ${ }^{17}$ Muy posiblemente por ello, el propio Primer Borrador del Libro Blanco

13 Este método de designación quedó fijado en la Moción aprobada, precisamente por el Senado, el día 20 de octubre de 1993. Gracias a su tenor, forman hoy parte de la delegación española cerca del Comité de las Regiones, junto a los Presidentes autonómicos, los representantes de las EE.LL. que designe la FEMP, de entre cargos locales electos o con responsabilidad política ante su órgano representativo. En la actualidad (y hasta febrero de 2006), se trata de los alcaldes de Madrid, Barcelona, Valencia y Langreo (Asturias).

Aun cuando no se menciona en el Decálogo, este método de designación es similar al contenido en la moción votada en la Comisión General de las Comunidades Autónomas del propio Senado el 24 de marzo de 1994, respecto de la delegación española cerca del Congreso de Poderes Locales y Regionales de Europa: seis miembros representarán a las CC.AA. y serán designados por éstas de común acuerdo; en tanto que otros seis representarán a las EE.LL., siendo designados por la Comisión Ejecutiva de la FEMP.

14 Así, según el artículo 4.6 de la Carta Europea de la Autonomía Local, «las autoridades locales serán consultadas, en la medida de lo posible, con suficiente tiempo y del modo adecuado, en los procesos de planificación y adopción de decisiones relativos a cuantas materias les afecten directamente".

15 El artículo 10.1 LBRL prevé la necesidad de ajustar las recíprocas relaciones entre la Administración Local y las demás Administraciones Públicas a los "deberes de información mutua, colaboración, coordinación y respeto a los ámbitos competenciales respectivos". Estos genéricos deberes quedan concretados en el artículo 62 LBRL, que asegura a las EE.LL. la "participación o integración en actuaciones o procedimientos conjuntos con la Administración del Estado y/o con la de la Comunidad Autónoma correspondiente", en aquellos casos en que "la naturaleza de la actividad de que se trate haga muy difícil o inconveniente una asignación diferenciada y distinta de facultades decisorias en la materia".

16 Así el Reglamento de la Cámara Baja (Bundestag) alemana prevé la celebración de audiencias en el seno del procedimiento legislativo, con la comparecencia de representantes de las EE.LL. Otro tanto sucede en los Parlamentos de los Länder, en relación con los municipios: es el caso de Baden Würtenberg, Sajonia o Brandenburgo, por disposición de sus respectivas Constituciones, existiendo preceptos de índole similar en Baviera, Sarre y Turingia, y siendo de facto la regla general en el resto (Font i Llovet 2005).

En Italia, el Proyecto de reforma constitucional actualmente en curso prevé la posibilidad de que las regiones emitan informe sobre determinados proyectos de ley en trámite en el Senado Federal, habiendo oído al Consejo de la Autonomía Local (art. 64) (Font i Llovet 2005).

17 Así en Canarias, donde por ejemplo existe una Comisión General de Cabildos Insulares (arts. 53 y ss. Reglamento Parlamento de Canarias), estando además prevista la participación de los Cabildos Insulares en muy diversos trámites parlamentarios. O en Galicia, donde la Ley 5/1997, de 22 de julio, de Administración Local de Galicia (art. 9), dispone que, siempre que sea posible y no se opongan a ello razones debidamente justificadas de interés público, se concederá a las asocia- 
para la Reforma del Gobierno Local en España del Ministerio de Administraciones Públicas incluye también una propuesta de participación local en la elaboración normativa ${ }^{18}$. Y en esa misma línea cabe inscribir la resolución de la Comisión Ejecutiva de la FEMP de 28 de junio de $2005^{19}$.

Y decimos que esta vía de refuerzo institucional es "fácilmente edificable» porque, como el propio Primer Borrador de Libro Blanco citado atinadamente apunta, bastaría una reforma de los Reglamentos del Congreso y del Senado para hacerla realidad en la tramitación parlamentaria de nuestros textos legislativos; lo cual sería por cierto deseable, pues de este modo quedaría normativamente realzada esta posibilidad de participación local. Y ello por más que las disposiciones actualmente existentes en uno y otro Reglamento (art. 44 Reglamento del Congreso de los Diputados; art. 67 Reglamento del Senado) constituyan sobrado acomodo para conseguir tal objetivo.

No sería éste el caso, sin embargo, respecto de la posible inclusión de las EE.LL. entre las instituciones dotadas de iniciativa legislativa, que conforme al artículo $87 \mathrm{CE}$ son hoy en día exclusivamente el Gobierno, el Congreso de los Diputados, el Senado, las Asambleas Legislativas de las CC.AA. y los ciudadanos a través de la llamada iniciativa legislativa popular. Una posible inclusión que sin duda se beneficiaría de cuantos argumentos favorables acabamos de esgrimir en relación con fases posteriores del procedimiento legislativo. Con todo, es claro que incluir las EE.LL. en ese elenco exigiría una reforma del mencionado artículo $87 \mathrm{CE}$. Lo cual no parece por otro lado descabellado (es idea bien común en nuestras CC.AA., que la prevén respecto de sus correspondientes municipios, y a propósito de sus propias leyes autonómicas), si bien sería preciso moderar la reforma mediante la exigencia de quorums suficientemente amplios de EE.LL., que a la par incluyeran umbrales relativos a su respectiva población: de esta forma se evitaría el riesgo de iniciativas excesivamente "localizadas"

ciones gallegas de municipios y provincias "la oportunidad de expresar su parecer sobre las disposiciones de carácter general y anteproyectos de ley que, en materia de régimen local, elabore la Junta de Galicia". Ello se hará efectivo "mediante un informe razonado y en un plazo mínimo de diez días".

18 Con la previa advertencia de que estas técnicas participativas no deberán en ningún caso servir como alternativa a la efectiva atribución de competencias, el Primer Borrador formula dos propuestas concretas: una, la posibilidad de que la Comisión Nacional de Administración Local elabore preceptivamente un informe sobre los anteproyectos de ley; otra, el desgaje de los aspectos competenciales de todo proyecto legislativo que se examine en las Cortes Generales, de manera que los aspectos materiales del proyecto en cuestión se examinen por la Comisión sectorial competente, en tanto que los competenciales lo sean separadamente, por la Comisión de Administraciones Públicas del Congreso y por su homóloga del Senado, o bien por "una Comisión de Administraciones Locales del Senado" (sic).

19 Que proclama el derecho de las EE.LL. a intervenir en los procedimientos normativos que les afecten; al ejercicio de la iniciativa legislativa en los términos que señale la correspondiente legislación autonómica; a la creación, dentro de las Asambleas Legislativas de las CC.AA., de un Consejo de Gobiernos Locales que emita dictámenes sobre los proyectos normativos que puedan afectar a las Entidades Locales y que formule enmiendas sobre las que la Asamblea Legislativa deberá pronunciarse. 
—nunca mejor dicho_-, y por ende inadecuadas, al menos para su tramitación en las Cortes Generales como representantes de la soberanía nacional.

B) Otro campo de refuerzo institucional, aún más difícilmente configurable, es la composición del Senado con representantes de las EE.LL. No faltan ejemplos en nuestra Historia constitucional. Por una parte, diversos textos constitucionales históricos españoles (las Constituciones de 1845, 1869 y 1876) abrían la elegibilidad como senador a personalidades con determinadas vinculaciones al mundo institucional local ${ }^{20}$. Si bien en estos supuestos la vinculación con la correspondiente institución local se limitaba a pretender una cualificación en la persona así declarada elegible, que unida a las demás previstas para poder ser electo senador, terminaba por dibujar un claro contraste frente a la mucho menos matizada composición de la Cámara Baja. Bien puede afirmarse que estas disposiciones producían sus efectos ex ante, es decir, con anterioridad a la elección como senador, siendo a partir de entonces —al menos formal u oficialmente- irrelevante la procedencia institucional del ya electo senador.

Por ello es de mucho mayor interés un segundo ejemplo constitucional, el previsto en el artículo 60 de la Constitución de 1869. Al fin y al cabo, este precepto sí incorpora una verdadera muestra de composición local, al menos parcial, del Senado, al establecer la elección de los senadores por una "Junta Electoral" constituida en cada provincia, y a su vez doblemente compuesta: de un lado, por "Compromisarios" electos por sufragio universal en distritos municipales; de otro, por los miembros de la correspondiente diputación provincial.

López-Medel (2003) por su parte entronca la representación de las EE.LL. en el Senado en el ya mencionado carácter bifronte de nuestro régimen local, de manera que tal representación vendría a funcionar como una suerte de factor equilibrador de la palpable tendencia "interiorizadora" de las EE.LL en el seno institucional de las correspondientes CC.AA. que —a juicio de este autorhabría venido produciéndose en los últimos años: de ahí que en su opinión, y sobre la base del artículo $137 \mathrm{CE}$, no quepa una interpretación excluyente de las EE.LL. del adjetivo "territorial» citado en el artículo 69.1 CE.

Más allá de fórmulas representativas como la del "más que local" Senado francés (que por su engarce institucional en un Estado unitario no resulta en modo alguno homologable), la idea parece abrirse paso en un país tan constitucionalmente cercano al nuestro como Italia. En efecto, el ya citado Proyecto de reforma constitucional en curso (art. 57) prevé la presencia en el Senado Federal, con voz aunque sin voto, de "representantes de las regiones y de las autonomías locales", en número de uno por región, respectivamente designado por el correspondiente Consejo de las Autonomías Locales (Font i Llovet 2005).

20 La Constitución de 1845 consideraba así elegibles para el Senado a quienes hubieran sido diputados provinciales o alcaldes en pueblos de 30.000 almas (art. 15). La Constitución de 1869 hacía lo propio respecto de quienes fueran o hubieran sido diputados provinciales cuatro veces o alcaldes dos veces en pueblos de más de 30.000 almas (art. 62). Mientras que la Constitución de 1876 permitía la elección como senador a quien fuera o hubiera sido diputado provincial o alcalde en capital de provincia o en pueblos de más de 20.000 almas (art. 22). 
Volviendo a nuestro país, nos fijaremos en distintos ángulos de esta posible e importante iniciativa:

a) Comenzaremos subrayando sus potenciales obstáculos. i) Uno de ellos sería la más que previsible resistencia de algunas CC.AA., especialmente las gobernadas por partidos nacionalistas, aunque no solamente éstas (es conocida la oposición a la idea por parte del Presidente de la Comunidad de Andalucía), que podrían quizá ver en la iniciativa el intento del "Gobierno de Madrid" de cercenar de este modo sus competencias, o en todo caso su margen de actuación política. Y es natural tal inquietud, por una doble razón: primera, la indiscutible y ya bien resaltada naturaleza bifronte de las EE.LL., que como hemos indicado las hace legalmente inmunes a toda pretensión interiorizadora procedente de alguna CC.AA.; segunda, la sólida legitimidad democrática de las EE.LL., sobre todo de los municipios, y su mayor proximidad a los ciudadanos, factores que sin duda juegan a su favor frente a las CC.AA., en medida comparable a como lo hacen en beneficio de las CC.AA. cuando el parangón lo es entre éstas y el Estado. ii) Un segundo obstáculo a esta reforma podría radicar en el hecho de que, ya en la actualidad, un elevado número de senadores acumulan a esta condición la de miembros de alguna o algunas EE.LL., lo que induciría a sopesar la mera necesidad de tal reforma: concretamente, y a fecha de 15 de agosto de 2005, treinta y cuatro senadores son también alcaldes; otros treinta y cuatro son concejales; cuatro pertenecen a Cabildos o Consejos Insulares, siendo dos de ellos Presidentes de Cabildo Insular; y nueve compatibilizan su acta de senador con su condición de alcaldes o concejales y miembros de Diputaciones Provinciales. En total, ochenta y un senadores, o lo que es lo mismo, sobre un número de miembros de Derecho de la Cámara de 259, casi un tercio, o el 31,27\%. Debe no obstante apuntarse que esta acumulación de mandatos senatorial y local (o locales), constitucional y legalmente permitida, es mero exponente de la personal trayectoria política del senador en quien concurre, y de los designios que respecto de él haya marcado su partido político, sin que sea fruto de una previa elección o designación por parte de las correspondientes EE.LL., que sólo en ese caso - y con las salvedades que después señalaremos - podrían aspirar a verse "representadas" por dicho senador. iii) Un tercer obstáculo podría llegar a ser el quizá escaso tiempo disponible por parte de quien fuera senador (en representación de la corporación local de que se trate), y a la vez ostentara un cargo electo de carácter local, máxime para los senadores que representaran a EE.LL sitas fuera de la Comunidad de Madrid. El argumento es en abstracto muy razonable, si bien no puede olvidarse que, como acabamos de ver, un número nada desdeñable de senadores compatibiliza hoy sin problemas dignos de mención tal función con un mandato local. iv) El cuarto y último obstáculo que citaremos es sin duda el más importante y consiste en el casi incuestionable hecho de que si el Senado llega algún día a incorporar senadores en representación de las EE.LL., dichos senadores quedarían de inmediato encuadrados en las filas de un grupo parlamentario, a su vez correspondiente a un determinado partido político (o a más de uno, como de 
ordinario sucede en el caso del Grupo Parlamentario Mixto): dicho de otra forma, la actuación de estos "senadores locales" quedaría desde su mismo comienzo articulada, no tanto por un interés local, cuanto por el del partido político al que el senador deba su elección. Con todo, y por más que el problema encarne una más de las múltiples manifestaciones de nuestra implacable y tentacular partitocracia (por lo que sin duda merecería una mayor atención), no podemos olvidar que así viene sucediendo respecto de los senadores designados por las CC.AA (art. 69.5 CE), sin que en ningún momento su existencia -al menos por este motivo- se haya visto cuestionada.

b) Otro aspecto digno de atención en esta idea sería el método idóneo para propiciarla. El tenor del artículo 69.2 CE y de sus subsiguientes apartados, centrados en la composición del Senado sobre base electoral conforme a sufragio universal, libre, igual, directo y secreto, con circunscripción provincial, insular o municipal (caso de Ceuta y Melilla) y con arreglo a un sistema mayoritario corregido; y el del $69.5 \mathrm{CE}$, comprensivo de particulares pautas de designación de los senadores autonómicos, arrojan pocas dudas: el único modo de hacer viable en nuestro ordenamiento una composición local del Senado sería la previa reforma constitucional.

En detrimento de la misma, quizá pudiera alegarse que la previsión constitucional de senadores locales, en tal condición llamados a representar a las EE.LL. que los hubieran designado, supondría una lesión del artículo 67.2 CE, en tanto y en cuanto proscribe la vinculación de diputados y senadores por mandato imperativo. Mucho se ha escrito sin embargo respecto de este problema en relación con los senadores designados por las CC.AA. ${ }^{21}$, siendo perfectamente aplicables a los potenciales senadores locales las conclusiones que, a propósito de aquéllos, con toda lógica estiman cohonestable el mandato representativo senatorial con la condición autonómica de su designación.

En punto a los detalles concernientes a la fórmula de elección de estos senadores locales, nos limitaremos a consignar tres ideas clave: i) La incorporación al Senado de miembros locales, junto con el obvio mantenimiento de los senadores de designación autonómica, exigiría una reducción del número de senadores de elección directa, toda vez que nuestra Cámara Alta cuenta ya con un elevado número de miembros en relación con el Congreso de los Diputados (cuyo número de miembros es a su vez excesivamente bajo, al situarse en el umbral mínimo de la horquilla 350-400 que el artículo 68.1 CE ofrece), de aproximadamente el 60\%, una proporción muy alta en el panorama comparado (Russell 2000). Dicho número, y por ende la proporción respecto del Congreso, deben reducirse porque una cuantía sensiblemente inferior de miembros es conveniente para la especificidad representativa de las Cámaras Altas, la territorial para nuestro Senado, al facilitar un trato menos formalizado entre los senadores y por tanto hacer más factible la negociación, en suma la cooperación.

21 Para una excelente síntesis del panorama doctrinal al respecto, vid. García-Escudero Márquez (1998). 
ii) El mecanismo de elección debiera ser en todo caso semejante al que el artículo 69.5 CE prevé respecto de los senadores autonómicos, más concretamente: primero, debiera ser un mecanismo de elección indirecta, es decir, habrían de ser las propias EE.LL. las que, conforme a la fórmula de especificación que se adoptara, designaran a sus senadores; la elección de senadores prevista en el citado artículo 60 de la Constitución de 1869 podría suponer una buena fuente de inspiración. Segundo, como el propio artículo 69.5 CE dispone para los senadores autonómicos, la elección debiera responder a criterios de representación proporcional. iii) Sería altamente conveniente asegurar la condición de senadores locales, con carácter nato, para los alcaldes de las grandes ciudades, debiendo quedar asimismo concretado lo que a estos efectos se entendería por "gran ciudad".

c) El último aspecto que sobre el tema abordaremos será el de los resultados que de la implantación de esta idea se podría esperar. Se trata de una propuesta muy interesante, sin perjuicio de que el —en nuestra opinión- principal lastre de nuestra democracia, esto es, el excesivo peso de los partidos políticos (al que poco más atrás nos referíamos), le permitiera rendir un fruto sólo limitado. Mas en cualquier caso, estaríamos ante una iniciativa que sin duda potenciaría la representatividad territorial de nuestro Senado, según hemos visto exigida por el mismo artículo $137 \mathrm{CE}$, largo, demasiado tiempo ignorado casi del todo en ésta su dimensión representativa. A la postre, la iniciativa no innova por completo, sino que sigue la pauta de representatividad territorial de los senadores designados por las CC.AA. (art. 69.5 CE), de ahí que sea difícil considerarla extraña.

Este refuerzo local de la representatividad territorial de nuestro Senado coadyuvaría asimismo a lograr lo que en ningún momento nuestra democracia ha conseguido, léase un bicameralismo más dispar y gracias a ello, más equilibrado. Más dispar, porque la existencia de senadores locales, en especial si son electos conforme a los criterios expuestos, unida a la de los senadores autonómicos, contribuiría a una composición senatorial suficientemente diversa de la del Congreso de los Diputados, habiendo ya señalado con anterioridad la importancia de este factor para un sistema bicameral. Y todo ello, por supuesto, con independencia de que la reforma constitucional que en esta Legislatura se pretende, termine también por alterar el régimen de elección del grueso de senadores, los actualmente electos sobre base provincial.

A mayor abundamiento, esa más intensa disparidad compositiva que un nuevo elemento local imbuiría en el Senado, proporcionaría a su vez una base más sólida para reforzar sus funciones, como es natural en relación con las propias del Congreso de los Diputados. En otras palabras, justificaría en mayor medida un posible refuerzo de tales funciones, muy particularmente las dotadas de contenido territorial, ampliando por ejemplo en favor del Senado los supuestos en que éste gozaría de prioridad en la tramitación legislativa, elevando los cortísimos plazos de tramitación de textos legislativos, o constriñendo en mayor grado la hoy casi omnímoda posibilidad de que el Congreso de los Diputados imponga en caso de conflicto su voluntad legislativa a la del Senado. 
Y ya lo indicábamos, citando a la mejor doctrina, más atrás: un bicameralismo más dispar y más equilibrado es a su vez un bicameralismo más eficaz.

\section{EPÍLOGO: LA POSIBLE REFORMA CONSTITUCIONAL DEL SENADO ACTUALMENTE EN CURSO HACE ESPECIALMENTE OPORTUNO EL MOMENTO DE PROPUGNAR UN SENADO EFICAZ EN LA REPRESENTACIÓN DE LAS ENTIDADES LOCALES}

No parece oponerse a ello el Gobierno. Y así, su Vicepresidenta Primera, en declaraciones de 2 de noviembre de 2004, señaló que la eventual representación de las EE.LL. en el Senado no constituye cuestión que el Gobierno descarte de antemano al socaire de la proyectada reforma constitucional de esta Cámara; bien al contrario, se trataría en su opinión de un asunto abierto al debate y a un posible consenso.

Parejo Alfonso $(2003,79)$ es en este sentido claro al apuntar que la existencia de un Estado con entes territoriales dotados de autonomía política demanda "un constantemente renovado equilibrio" entre unidad y diversidad y una "actuación sinérgica", con vistas a un resultado de conjunto que sea coherente. No en valde, como afirma Sosa Wagner $(2004,59)$, nos hallamos ante un problema de fe y confianza en el sistema plural que la Constitución patrocina", una fe y una confianza que deben en todo caso extenderse asimismo a las EE.LL.

Pero también nos hallamos, añadiríamos nosotros, ante un problema de confianza (que es lo mismo que la fe) en el propio Senado, pues si esta Cámara mantiene su insatisfactoria representatividad de las EE.LL, es del todo seguro que otros órganos jugarán ese papel. Así ha sucedido en otras muchas áreas, como por ejemplo en la fiscal y financiera, donde el Consejo de Política Fiscal y Financiera, presidido por el Ministro de Economía y Hacienda y adicionalmente compuesto por los Consejeros autonómicos competentes, se ha erigido en el órgano de cooperación en esta materia que el Senado (o quizá más concretamente su Comisión General de las CC.AA.) habría debido constituir. Y de este modo la cooperación interadministrativa en materia de régimen local quedará del todo inmersa en los poderes ejecutivos: ventaja, entre otras, una mayor agilidad en la toma de decisiones; desventaja, también entre otras, una menor legitimidad democrática de las medidas que se pudieran adoptar.

De hecho, no apunta a otro objetivo la ya veterana Comisión Nacional de Administración Local (art. 117 y ss. LBRL), como órgano tradicionalmente encargado de la cooperación bilateral entre Estado y Administración Local. Aunque también se orientan a ello dos órganos de reciente creación (por la Ley 57/2003, de 16 de diciembre de Medidas para la Modernización del Gobierno Local), cuales son la Conferencia Sectorial de Asuntos Locales (indirectamente prevista en el artículo 120bis LBRL) y la Conferencia de Ciudades (art. 138 LBRL).

La Conferencia Sectorial de Asuntos Locales, constituida por cierto el 17 de enero de 2005 (en clara muestra gubernamental de pretender aprovechar estos 
nuevos mecanismos orgánicos de nuestra legislación de régimen local), es la primera manifestación orgánica de cooperación trilateral en la materia, al aunar en su seno a representantes del Gobierno (la preside el Ministro de Administraciones Públicas), junto a representantes autonómicos (los Consejeros competentes en Administración local) y representantes de la propia Administración local (designados por la FEMP). Si bien su Reglamento interno está aún pendiente de aprobación, su función bascularía esencialmente sobre dos tareas básicas: una, la de informar con carácter previo las leyes y tratados con relevancia en el ámbito local; otra, la de impulsar la cooperación y la coordinación entre los tres niveles territoriales del Estado en materia de régimen local ${ }^{22}$.

La Conferencia de Ciudades, aún no constituida, estará compuesta por los mismos representantes que configuran la Conferencia Sectorial de Asuntos Locales, a quienes deberá añadirse a los alcaldes de los llamados municipios de gran población. Pronto conoceremos si esta oportunidad en favor de un Senado más representativo, más territorial en la más amplia acepción de este término, se ha sabido o no aprovechar.

ABSTRACT. The Spanish Senate is bound to represent the territories. The three main types of Spanish territories are: municipalities, provinces and autonomous communities (article 137 of the Spanish Constitution, S.C.). In the end, local governments existed long before the Constitution, and certainly before autonomus communities were born. All the more so local governments, especially municipalities, make up the best government examples of freedom and democracy. It is basicly for both reasons that the Constitution confers also local governments with "autonomy in the management of their respective interests" (article 137 S.C.). The Senate has proved ineffective in representing Spanish territories, notwithstanding its on the other hand proven ability to perform its remaining constitutional functions, those it carries along as "the other" Chamber of the Spanish Parliament as a whole (article 66.1 S.C.). In any case this ineffectiveness in territorial representation, certain vis à vis autonomus communities, shows even worse in relation to local government bodies, since the need and convenience for the Senate to become an effective representation instrument also for local governments has always been neglected, not only by government actors but by the academia as well, definitely by the public opinion at large. A real shame, for the fact that the Senate might one day perform as a useful representative of local government bodies is not only defendable from the political point of view, but also viable from the technical, legal one. In addition the time is particularly right, projects for a constitutional reform of the upper Chamber being currently underway. 